\title{
Impact of Macroeconomic Control Policy on Real Estate Market in Zhengzhou
}

\author{
Weirui Chu ${ }^{*}$, , Jianfei Zhang', Hao Zhou ${ }^{2}$ \\ ${ }^{1}$ College of Architecture and Civil Engineering, Nanyang Institute of Technology \\ ${ }^{2}$ Civil Engineering College of Civil Engineering Professional Level 16, Nanyang Institute of \\ Technology \\ *Corresponding Author: fdbd.happy@163.com
}

Keywords: Macroeconomic Control Policy, Real Estate Market

\begin{abstract}
The real estate industry is the basic, mainstay and leading industry of national economy. The real estate industry, in the process of development, under the policy of national macroeconomic control, shows significant fluctuations and volatility. The paper analyzes the impact of financial policy, land policy and tax policy on the real estate industry of Zhengzhou. In the context of macroeconomic control policy, to strengthen strategic planning and management, expand the diversification of financing channels, improve the core competitiveness of enterprises and other coping strategies should be taken. Under the regulations and policies, such coping strategies, can promote real estate industry of Zhengzhou to avoid risks and seize opportunities, to achieve sustained, stable and healthy development
\end{abstract}

\section{Development status of real estate industry in Zhengzhou}

Zhengzhou, the capital of Henan Province, is located in the north central region of Henan, near the Yellow River in the North, nestled the Song Mountain in the West. Huanghuai plain is in the southeast of Zhengzhou. There are 12 counties/cities or districts in Zhengzhou. Total area is 7446.2 square kilometers while the urban area is 1010.3 square kilometers. Compared with other cities, the development of real estate industry in Zhengzhou is relatively late. However, a series of national macro-control policies accelerates the development of the real estate industry of Zhengzhou rapidly. In 2003, the development of the real estate industry of Zhengzhou was in full swing, showing a "blowout".

As China's economic development has entered a new period of normality, the real estate industry, with the sustained and rapid development for twenty years, has been entered the period of growth bottleneck, policy improvement, structure adjustment and quality upgrade.

The real estate market report of 2015 shows that: judging from recent market fluctuation, the real estate industry has experienced the overall market boom in 2013 and entered a comprehensive slump in 2014. The real estate industry of Zhengzhou is going through this storm. Regardless of any grade of high, medium and low products, have suffered different levels of cooling. The trading volume of real estate is declined sharply. The price is dropped to its lowest. The growth of financial investment slowed significantly. Housing starts declined in frequency. All indicators on the real 
estate market fell [1].

\section{National real estate macroeconomic control policy and its effect analysis}

\subsection{Analysis of loan policy}

Policies to stimulate the real estate play a very important role."Notice of perfecting the differentiated housing credit policy relevant issues by China Banking Supervision and Management Committee of the People's Bank of China”, has been enforced in September of 2010. For loans to buy the commercial house, the down-payment ratio is adjusted to $30 \%$ and above; the regulations, that for second-home buyers, the minimum down payments are required to be at least $50 \%$ and mortgage interest rates no less than $110 \%$ of the benchmark interest rates, is implemented strictly(Genxing Yao,2014).

On January 26, 2011, Premier Wen Jiabao presided over an Executive meeting of the State Council. It pointed out that national real estate macroeconomic control policy should be made further research and deployment. For second-home buyers, the minimum down payments are required to be at least $60 \%$ and mortgage interest rates no less than $110 \%$ of the benchmark interest rates.

"Notice on Further Improving the Housing Financial Services by China Banking Supervision and Management Committee of the People's Bank of China", has been issued in 2014. For loans to buy the first housing, the minimum down payments are required to be at least $30 \%$ and minimum mortgage interest rates no less than $70 \%$ of the benchmark interest rates.

For families with a home and related loans be settled, apply the loan for commercial housing to improve the living conditions, banking financial institution should implement the first suite mortgage policy (Yuanpeng Yu,2011).

\subsection{Effects}

The national policy in 2010 and 2011 is a more obvious control of the real estate industry. Main purpose is to avoid the accumulation of personal housing. By the macroeconomic control, the state curbs the ongoing developing real estate industry, controls the momentum of the rapid increase in real estate investment, and maintains a stable development of the real estate industry.

2014 policy in 2014, improves the purchasing power of Chinese residents effectively. Therefore, the real estate industry, following macroeconomic control policies implement, may have a certain rebound. Real estate regulation has the following features:

Stages of macroeconomic control are reflected in different phrases step by step. It focuses on resolving the prominent contradictions at different stages, maintaining the stability and continuity of economic development, with a small negative effect

Systematic and comprehensive of macroeconomic control. According to control objects, different methods and means of control are chosen. The real estate industry is overall controlled by the integrated use of legal and economic instruments and its effect is more obvious.

National macroeconomic control has different guidelines for each object and it should be distinguished. Not only should it control the real estate investment rate, but also curb investment demand, to protect the purchase enthusiasm of ordinary citizens (Yuanpeng Yu,2011). 


\section{Impact of macroeconomic control policy on real estate market in Zhengzhou}

\subsection{Impact of financial policy on the real estate industry of Zhengzhou}

From the aspect of financial supply, national debts and credits enhanced the investment pulling force. Since 1998, to the expansion of domestic demand, China has been implementing a more proactive fiscal policy and prudent monetary policy. In 2014, China adopted the new real estate loan policy. The original down payment ratio, that is not less than $60 \%$, is adjusted to be not less than 30\%. Last year, real estate investment growth slowed down. Inventories rose and prices fell back. The Central Bank has adjusted the mortgage policy, but, given the high percentage of down payment on the second housing, is continuing to limit the release of improvement housing demand. During the period of high price housing, the credit policy is mainly following real estate macroeconomic control. It is relatively strong and mostly short term emergency measures. And adjustment methods are combined with administrative measures. In this way, it is difficult to adapt to the current real estate situation. With the new central bank's policy issued in 2014, it is the new impetus to the real estate industry in Zhengzhou, and brings promotion and development to the Zhengzhou economic (Chunquan Dai,2011).

\subsection{Impact of land policy on the real estate industry of Zhengzhou.}

Land is the carrier of the construction project, is the lifeblood of the real estate enterprises. In 2005, China issued the regulations prohibiting the use of agricultural land for commercial. Some of the new projects, in Zhengzhou, may not be approved due to the strict examination and approval of land. It impacts the new projects and forward project reserves. Thus it affects the further investment and economic development. Now, less and less available land target, more and more commercial land use requirement, makes more difficult to get the land, as for the real estate business. The demand for land, of more than 600 real estate enterprises in Zhengzhou, is increasing. Such relationship between supply and demand makes the supplier in straitened circumstances. Therefore, to build a New Socialist City and ease the relationship of land supply and demand, Zhengzhou municipal government conducted a series of demolition and reconstruction of urban villages in Zhengzhou. After the completion of the transformation of the village in Zhengzhou City, the construction land will be significantly reduced. So, real estate in Zhengzhou might come into a bottleneck period by that time, or into a new period of development with the development of society. In the case of excavation of land resources, real estate industry in Zhengzhou nowadays will continue to grow steadily.

\subsection{Impact of tax policy on the real estate industry of Zhengzhou.}

As early as 1994, China started to levy land value-added tax. Collection of land value-added tax in our country is to carrying out macroeconomic control on real estate industry and primarily to imposing a tax on real estate development enterprises to adjust their earnings. Since June 1, 2005, for individuals to resale the housing purchased for less than two years, sales tax should be charged according to the sum of sales revenue when the transaction is made; for individuals to purchase ordinary housing for more than two years (two years), the resale are exempt from sales tax. For individuals to purchase non-ordinary housing for more than 2 years (two years), sales tax should be charged according to the amount that sales revenue minus the purchased price when the resale is made. On January 27, 2011, the time of collection of housing sale tax is from more than 2 years extended to more than 5 years. And the transfer fee is imposed. On March 20, 2015, the time of collection of send-hand housing sale tax was adjusted from 5 years to 2 years again. Such 
shortening of time requirement of the sale tax exemption makes the second-hand housing market heat up. According to the lasts housing tax exemption policy, individuals to resale the ordinary housing purchased for more than2 years ( 2 years), shall be exempted from sale tax. As for the ordinary housing and the ordinary housing standard, it should be executed according to the previous policy. It does not mean that, the sale tax is exempted for all housing for purchased over 2 years, since more than 144 square meters housing is not included.

\section{Coping strategies from real estate industry of Zhengzhou under the national macroeconomic control policy}

Under the national macroeconomic control policy, the real estate industry of Zhengzhou will be faced with new challenges and opportunities. Due to its geographical conditions and influence of national policies, as well as the limits of its own development strategies, real estate industry in Zhengzhou has not formed a good consciousness of risk aversion. In national economic situation, to develop Zhengzhou and other central hub cities was clarified, which provides a great opportunity for Zhengzhou.

So, as for Zhengzhou real estate businessmen, it seems to be very important whether they are able to get full understanding of current national macroeconomic control policy, analysis the development of China's reality and the existing problems, recognize the direction of real estate development and prospects for future development in advance. Based on these understanding and analysis, it is important that to make a scientific and feasible coping strategy in line with the development of the industry, and to find a way out for the development of real estate enterprises in Zhengzhou City.

\subsection{To strengthen strategic planning}

Enterprise strategy is the development direction of the enterprise. Only determining the direction of development, the enterprise can do the right thing in the right way. With the introduction of "the six national regulations" and the new real estate credit policies, the real estate market has undergone tremendous changes. Real estate enterprises must adapt to the market changes, and make the appropriate strategy in time.

Real estate investment risk is sort of high, which involves social risks, natural risks, policy risks, technical risks, international risks, etc.

Among these risks, economic risk is the main risk, which influenced strongly and can be predicted and avoided, including market interest rate risk, capital liquidity risk, purchasing power risk, etc.

In recent years, along with the gradual transfer of national economic system and the introduction of a series of macroeconomic control policy, real estate investment risk generally reveals the following trends: economic risk reduces; technical risk and political risk increases and geographic variation in real estate investment risk decreases. Therefore, on handling with different types, probability and magnitude of risk, enterprises should take different measures and methods, strengthen risk prevention, so as to avoid risk of real estate investment or to minimize the risks(Zhen Jiang,2011).

Wu Youfu, CEO of Coastal Group, said, "With the adjustment of national macro policy, real estate enterprises will face more fierce competition in the future.

Talent competition is one of the most important aspects. We are fully aware that the cultivation of talent affects enterprise's long-term strategy and foundation of enduring significance. So, the real estate industry should change the vision from the external environment to the internal talent completion, deepen and carry out the cultivation of outstanding talent strategy. Enterprises should 
foster more talents, with international vision and leadership, to promote the long term development of the enterprises.

\subsection{To strengthen strategic management}

The real estate industry investors must pay more attention to the national macroeconomic control policy. Seeing the essence through the phenomena. Based on the current market status, it may be judged that the Government is possible to implement the policy. Enterprise leaders should strengthen the strategic according to its actual situation. Thus, the reasonable arrangement can be made in advance of related policy implement, and by the good use of the policy to make the profit, or make the right choice to minimize the losses, when the corresponding policies is carried out.

\subsection{To diversify of financing Channels}

Funds source of current real estate are mainly from bank loans. The national macroeconomic control limits the loan amount or raises the interest rate, so multiple financing channels should be seek to reduce the influence of national macro-control and market risks. And how to establish relatively perfect financing channels has become the key issue of the real estate industry in nowadays.

\subsubsection{Bank loan}

Funds source of current real estate are mainly from bank loans. Now, at least $70 \%$ of the real estate business fund is from commercial banking system. Real estate enterprises rely on a single source of funds in a commercial banking system. Not only does it increase the risk, but also make real estate funds tight. To change such situation of single fund source is imminent.

\subsubsection{IPO financing}

IPO is the best way of financing. IPO financing can minimize financial risks, reduce capital costs, and further improve the internal industrial structure. According to the National Development and Reform Commission statistics, as of early 2015, there have been Jianye Group, Gemdale Group, Guangzhou Evergrande Group, more than 80 real estate enterprises listed in the stock market. Real estate enterprises can raise funds through the listing. The funds can be used as registered capital permanently, with no reimbursement deadline. The usage of funds is relatively wide. Listed real estate enterprises have the obvious advantage as for some larger projects. However, the listing is pretty tough. So to be listed may be an extravagant hope for most real estate enterprises. It is impossible for small and medium enterprises.

\subsubsection{Bond financing}

Real estate debts are an important part of international bonds. But, in China, real estate bonds are rare. It does not match with the pace of industrial development. In 2004, China issued the "Opinions on promoting the capital market reform and stable development by the State Council". Such policy is extremely beneficial to help real estate companies issuing the bond. Thus, financing channels of the real estate industry has become more diverse, providing a better environment for development.

\subsubsection{Mezzanime financing}

Mezzanine financing of China real estate industry is in a form of investment between debt and equity. There are many financial products that can be innovated in mezzanine financing. Some can 
be transformed into bonds, while some can be transformed into equity. There are many combinations of real estate finance. Debt and equity can be combined or separated. Mezzanine financing brings more innovation space to real estate industry in capital. For real estate developers, mezzanine financing is an important method, which is flexible, with the feature of raising funds depending on the different projects.

Zhengzhou real estate industry has developed for more than 20 years, but the housing construction structure is still too simplex. The real estate developers need to know what consumer need and what they can afford to get a better profit. Do what the market needed.

And, what the consumer prefers is the product with much more potential and added value. The real state can be more competitive only when they improve their innovation ability.

The logo is a symbol of a real estate enterprise for consumer to distinguish. An excellent logo should have a special quality, which is honest and trustworthy. Only with honest and trustworthy, the consumer can accept and trust the logo, and only with this quality and enterprise can be successful.

\section{Conclusion}

In order to face the changing state macro control, and the bottleneck of development, Zhengzhou real estate enterprise should make a strategy decision combined with its own advantages. It's also necessary to develop the financing channels and to enhance the competitiveness for future development.

\section{References}

[1] Dai C Q and Xu Q 2001 Real Estate Development (Beijing: Tsing Hua University Press)

[2] Xu H 2010 On Real Estate Management Measures (Henan Science and Technology) Vol 5 p 57-61;

[3] Yao G X 2014 Real Estate Enterprise Project Management Guide (Beijing: Chemical Industry Press)

[4] Yu Y P 2013 Real Estate Development Enterprise Financial Management and Cost Control Management Practice (Beijing: China Machine Press)

[5] Yu Y P 2011 Real Estate Development Enterprise Project Management Practice (Being: China Machine Press)

[6] Jiang Z 2011 Research on Real Estate Industry Management Measures (Shan Dong Science and Technology Information) Vol 18 p 32-47. 